\title{
Food in Focus: Youth Exploring Food in Schools Using Photovoice
}

\author{
Rebecca Ann Spencer, $\mathrm{PhD}^{1}$; Jessie-Lee D. McIsaac, $\mathrm{PhD}^{1,2}$; Melissa Stewart, $\mathrm{BSc}^{1}$; \\ Sara Brushett, BSc ${ }^{1}$; Sara F.L. Kirk, $\mathrm{PhD}^{1}$
}

\begin{abstract}
Objective: As part of a study exploring school food environments, this study aimed to understand youth perspectives of school food.

Design: Photovoice, a qualitative visual methodology, was used to engage participants through phototaking, with goals of enabling reflection, promoting dialogue, and facilitating change.

Setting: Participants were recruited through 2 youth-focused community organizations in Nova Scotia, Canada.

Participants: Seven youths took part: 3 from a rural area and 4 from an urban center.

Phenomenon of Interest: Youth perspectives on school food environments.

Analysis: The photovoice process of selecting, contextualizing (using the SHOWeD method), and codifying was used for analysis.

Results: Four themes were identified. First, spaces and places were important to youth food experiences. Second, key components of food environments were identified as quality, variety, time, and price. Third, the relation between food and social influence was highlighted. Fourth, the importance of amplifying youth voice was discussed.

Conclusions and Implications: Youth emphasized a desire for greater variety and quality in affordable school food options and the opportunity to be involved in decision-making regarding school food. Future research in other contexts and across larger samples is warranted to extend these findings to help inform stakeholders in school food policy and program implementation.
\end{abstract}

Key Words: nutrition, photovoice, school food, youth experience (J Nutr Educ Behav. 2019; 51:1011-1019.)

Accepted May 16, 2019. Published online June 14, 2019.

\section{INTRODUCTION}

It is well established that children who are nourished have improved health outcomes, increased capacity for learning, and better academic outcomes. ${ }^{1,2}$ Schools have been identified as an effective setting for health promotion, particularly regarding child nutrition, with evidence exploring the benefits, opportunities, and challenges of policies and programs aimed at creating healthy school food environments. ${ }^{3,4}$ Although no set definition exists for school food environments, they are often characterized by the availability and quality of food, as well as spaces where students and staff purchase, consume, and otherwise encounter food during school hours. ${ }^{5-7}$ Research gives context to these environments by considering the physical, social, political, and economic elements that influence these spaces, including the presence of programs and policies, food culture, and resources available. $^{6,8,9}$ There has been significant effort in Nova Scotia to shift toward

\footnotetext{
${ }^{1}$ Healthy Populations Institute, Dalhousie University, Halifax, Nova Scotia, Canada

${ }^{2}$ Faculty of Education and Department of Child and Youth Study, Mount Saint Vincent University, Halifax, Nova Scotia, Canada

Conflict of Interest Disclosure: The authors have not stated any conflicts of interest.

Address for correspondence: Rebecca Ann Spencer, PhD, School of Health and Human Performance, Dalhousie University, 6230 South St, PO Box 15000, Halifax, NS B3H4R2; E-mail: Becky.spencer@dal.ca

(C) 2019 The Authors. Published by Elsevier Inc. on behalf of Society for Nutrition Education and Behavior. This is an open access article under the CC BY-NC-ND license. (http:// creativecommons.org/licenses/by-nc-nd/4.0/)

https://doi.org/10.1016/j.jneb.2019.05.599
}

healthier school food environments. The provincial government introduced 1 of the first School Food and Nutrition Policies in Canada in 2006, and there has been additional support from ongoing research, the nonprofit sector, and other stakeholders. ${ }^{2,10-12}$ Research on adherence to School Food and Nutrition Policies found mixed uptake and impact, suggesting a need for better understanding of the mechanisms that support implementation. 13-16 In particular, there is a need to engage key stakeholders more effectively to explore the complexities of the school food system and their role within it. Previous work identified youths as major stakeholders who wish to be more engaged in their school food environments. ${ }^{17-19}$

Although youths are the primary recipients of school food interventions and the literature highlights the importance of youth engagement, gaps remain regarding the extent to which youths' experiences and perspectives are invited in discussions 
about school food policy and program development. ${ }^{20,21}$ Although youths are typically involved in assessing health policy outcomes, challenges and opportunities regarding implementation are primarily framed through the lens of adults such as parents, school staff members and teachers, and policy makers, and students are rarely provided an opportunity to offer meaningful, critical reflections on their experiences with school food. ${ }^{18,21-23}$ This underrepresentation of youths is underexplored in the literature and a missed opportunity for successful and sustained implementation of interventions. Indeed, research ${ }^{24-26}$ showed that engaging youths in research and policy and empowering them to share their perspectives can bring new understanding to traditional views and lead to increased intervention success.

As part of a multicomponent study exploring the complex systems embedded in school food environments, this study sought to incorporate youths' voices into the discussion, using photovoice. ${ }^{27}$ The objectives of this study, aligned with the typical goals of photovoice, ${ }^{27}$ were to enable youths to record and reflect on strengths and concerns they had regarding their school food environment; promote critical dialogue, give voice to students' experiences, perceptions, and concerns through visual methods; and facilitate reaching decision makers with evidence relevant to the experiences and ideas of youth participants.

\section{METHODS}

\section{Study Design}

Photovoice is a specific visual methodology used to engage participants through photo-taking. ${ }^{27}$ Based on theoretical approaches that focus on equity and inclusion, the goals of photovoice are to enable reflection, promote critical dialogue, and reach decision makers. ${ }^{27-29}$ Allowing participants to represent their communities through photographs permits their perspective to be seen and for them to act as change agents; photographs have the potential to take on broader political, social, and emotional meaning. ${ }^{27-29}$ Photovoice can offer richer data than traditional research methods and can promote participant self-esteem and community engagement. $^{27,29}$ Photovoice is appropriate for use with youths; it can promote their engagement in community issues and offers opportunity for autonomy, creativity, and inspiration. It has also been used and applied successfully in issues relating to youth health and well-being, including nutrition. ${ }^{28,30-35}$ This project was reviewed and approved by the Dalhousie University Institutional Review Board, and written informed consent was gathered from all participants.

\section{Participants}

To avoid burdening the school system, participants were recruited through 2 community organizations in Nova Scotia, Canada, rather than directly through schools. One organization was located in an urban center and 1 was in a rural community. Liaisons from the community organizations facilitated youth recruitment by conducting purposeful sampling through existing programming. The only inclusion criteria were being a high school student (grades 10-12) in Nova Scotia an interest in and ability to take photographs. Once youths had expressed interest in the community liaison, they were connected with a member of the research team to establish informed consent. Seven youths, average age 16 years, took part in the study: 3 from the rural area and 4 from the urban center. Five youths chose to disclose gender as female-identified. Together, 4 schools under 2 regions of the province were represented. Although no youths dropped out of the study, 1 missed a focus group analysis session owing to a family obligation.

\section{Procedures}

This study followed the process outlined by Wang. ${ }^{35}$ The research team was assisted by staff from a local center for youth development. In each location, 3 meetings were held with the youths: an initial training workshop and 2 follow-up focus groups. The initial 4-hour workshop included an introduction to the project, developing familiarity with ethical procedures for photo-taking, instruction from a photographer, and time for practice. The workshop concluded with a brainstorming session to spark critical thought regarding the research topic. Between the initial workshops and each follow-up focus group, youths were given 1-3 weeks to take photographs. Many participants used their own mobile phones to take photographs; 3 from the urban location borrowed digital single-lens reflex cameras from their community organization. All photographs were transferred to the research team electronically using the university's secure file exchange system. Participants submitted 7-36 photos each (average, 19 photos/participant), and a total of 151 photos were submitted for the project. Two copies of each photo were printed: 1 was given to the participant who took the photo and 1 was kept for analysis.

The participatory process of analysis took place at each follow-up focus group through a process of selecting, contextualizing, and codifying, as outlined by Wang and Burris, ${ }^{27}$ Wang et $\mathrm{al}^{29}$ and Wang. ${ }^{35}$ Selection involved giving participants time to review their photographs and choose a couple for discussion. Contextualizing involved participants discussing the photo and why they selected it, giving meaning to the photographs. The researchers used the SHOWeD method to give context to photographs by asking participants: What do you See, what do you think is really Happening, how does what is happening relate to Our lives, Why does the issue, problem, strength exist, and what can be Done about it? ${ }^{29}$ Finally, the process of codifying engaged participants in a discussion and analysis of their photographs through a participatory thematic analysis in which participants sorted and grouped photographs and discussed themes and trends. In each location, 2 of these focus groups occurred after the initial workshop, because after the first focus group, participants determined that they wanted the opportunity to take more photographs and repeat the process. Each brainstorming session and follow-up focus group discussion was audio-recorded and transcribed verbatim to permit the use of direct quotations. Because of the participatory nature of this analysis, no measure of thematic saturation or coder agreement was explored. 


\section{RESULTS}

Four themes were uncovered through this study and are described subsequently.

\section{Theme 1: Spaces and Places Are Important to Youth Food Experiences}

Youths discussed the importance of spaces and places, which provide context for food experiences, such as that in Figure 1a. Participants took photographs of food in a variety of spaces, compared and contrasted those spaces, and grouped photographs according to where they were taken, as in Figure $1 \mathrm{~b}$ and c. Common spaces included food from home, school cafeterias, other places at school, and restaurants or other off-campus locations. Other places at schools discussed by youths included breakfast programs, learning centers, food baskets, and vending machines. Vending machines were perceived as a way to get quick snacks but difficult to supply with nutritious food. One student said, "I don't know if you can put healthy food in a vending machine." Breakfast programs were highlighted as valuable by youths, primarily as a point of access (Figure 1d). A student said, "It's a big part of our school. Like, pretty much everyone in the school has been there at least at some point."

Generally, youths compared foods from home and school, usually with the perception that food from home seemed healthier and more appetizing, primarily related to aspects of quality and variety. Overall, youths were unimpressed with the quality of food offered in school cafeterias, although they recognized challenges associated with serving many students, cafeteria requirements, and costs, and they noted its convenience when they did not pack a lunch. Overall, youths though that school

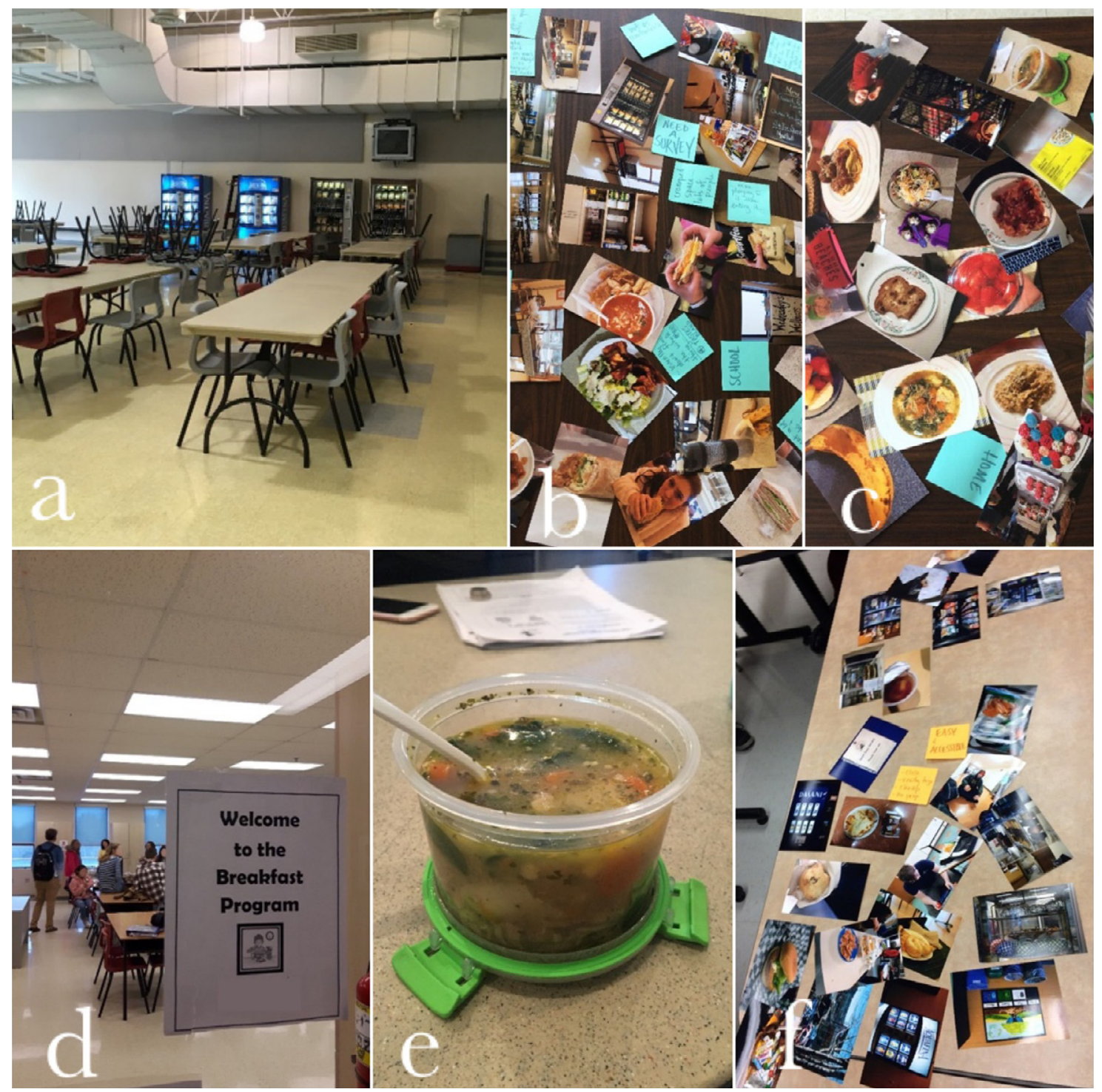

Figure 1. Photos from theme 1. (a) Example of space for eating at school. (b, c) Examples of photo groupings comparing spaces and places for eating. (d) Image highlighting the school breakfast program. (e) Example of food brought to school from home. (f) Example of photo grouping of food deemed accessible. 
cafeterias offered limited menus that emphasized meat and prepackaged foods with little variety or ability to customize to individual preferences or dietary requirements. One student said, "If you have any, like, food limitations, you're done." Youths wanted to see more variety, excitement, and foods that made them feel nourished. Some participants brought food from home regularly (Figure 1e) and noted that it was healthier and affordable and permitted autonomy, whereas others bought food at school for convenience. Restaurants or off-campus sources of food were also highlighted as important. Youths noted that they preferred the quality and presentation offered by restaurants and emphasized the value in places that offered good vibes for social interaction, although they noted that those places were more expensive. They also noted value in places that offered real food such as freshly baked bread, which seemed more comparable to foods from home. Finally, youths noted that their peers tended to eat at fast-food places during the day because of their proximity, speed, convenience, and low cost.

Related to the idea of spaces and places was the concept of access. Youths described accessible food as close by, ready, fast, inexpensive, and requiring little preparation (as in the photo grouping in Figure 1f), whereas they classified food as less accessible when it was expensive or required more time, preparation, or both. The youths also discussed weather and transportation as being highly tied to access. For example, 1 said, "If you don't have your license [...] and it's, like, snowing or raining, very few people go out." Accessing a vehicle was important for transportation to restaurants, as well as a place to sit and eat or socialize.

Theme 2: Key Ingredients: Quality, Variety, Time, and Price

The youths also identified several important characteristics of food environments youth as significant for their school food experiences: quality, variety, time, and price. Quality, or the extent to which food was perceived as appetizing, tasty, nourishing, and healthy, was identified as a particularly important subtheme discussed and featured in photographs by all youths. School cafeteria food was described as lacking quality, in that it was perceived as bland and overly processed. One participant said, "This is what I usually get from the cafeteria. That's the food that looks like plastic." Youths noted that cafeteria food had to meet certain nutritional requirements but did not taste good and was not perceived as healthy. For example, 1 said,

It seems like they are trying to make it healthy, but it's really not [...] like, they make pizza, but it's not like real pizza.

Cafeteria food was often described as lacking variety, color, and flavor; an example is shown in Figure 2a.

Youths recognized that it can be challenging to serve quality food in school cafeterias. One said,

I just like a nice meal, [...] which isn't really ... practical to think that you could have that at the cafeteria because it's not the same environment and they have a lot of people to serve.

However, youths also pointed out that some foods from home could be served in schools as well. They also compared fresh and processed foods with foods from home labeled as fresh, and foods from schools labeled as processed, as illustrated in Figure $2 \mathrm{~b}$, in a photo grouping the youths described as wanting less of. Bringing food from home also related to autonomy, in that youths had more ability to choose and to season items as they wished. They noted that some youths enjoyed less healthy and processed food sometimes, and that school cafeterias offered quick, accessible options, but they also wanted healthy options that were appetizing and tasted good. One youth described choosing lunch (Figure 2c and d):

\section{Some days, I'm good. I pack my lunch and I actually try. Then, other days, I just pull this out of the freezer and put it in the micro- wave. So, there's, like, no in- between. It's one or the other.}

Variety, or the availability and accessibility of diverse food options, was also identified as important. Youths noted that school cafeteria menus tended to have daily offerings with little variety. One said, "They have the same options pretty much every day [...] it gets so tiring." They also perceived cafeteria menus as emphasizing meat and thought that there were few options for students with alternative dietary requirements or preferences. One described the photo in Figure 2e:

That's the main meal that you can buy. [...] It's all meat, and we do have people at the school that're vegetarian. So, we don't really have a lot of options for vegetarians. [...] It's kind of disappointing.

Another echoed, "If someone has, like, celiac [...] they cannot buy anything at the cafeteria." Connecting closely to this subtheme of quality, youths underscored the importance of offering diverse and colorful options, especially regarding fruits, vegetables, and seasonings, which were perceived to be fresher and more nutritious. A participant relayed this sentiment by saying, "I feel like it would be beneficial for them to have, like, more of a variety of fruit." This is highlighted by an image of an empty fruit bowl in Figure $2 \mathrm{f}$.

Closely connected to the subthemes of quality and variety was the subtheme of time, which frequently emerged in both discussion and photographs. Youths understood that healthy, high-quality food took longer to prepare. They noted this both in preparing their own food and mentioned that they thought it would require more time for school food services to provide quality and variety. One said,

The cafeteria, they don't have all the time in the world to spend making meals, so [...] they have to make meals that they know they can get done.

They noted that cafeterias seemed to be operating under the constraints of time, staff, and resources, and they did not fault cafeteria staff for this. One participant acknowledged time challenges by opting to mix a powdered breakfast drink:

It's a lot of protein in 1 shake, and I, like, down it, and sometimes it hurts my stomach [...] They make me full without me actually needing 


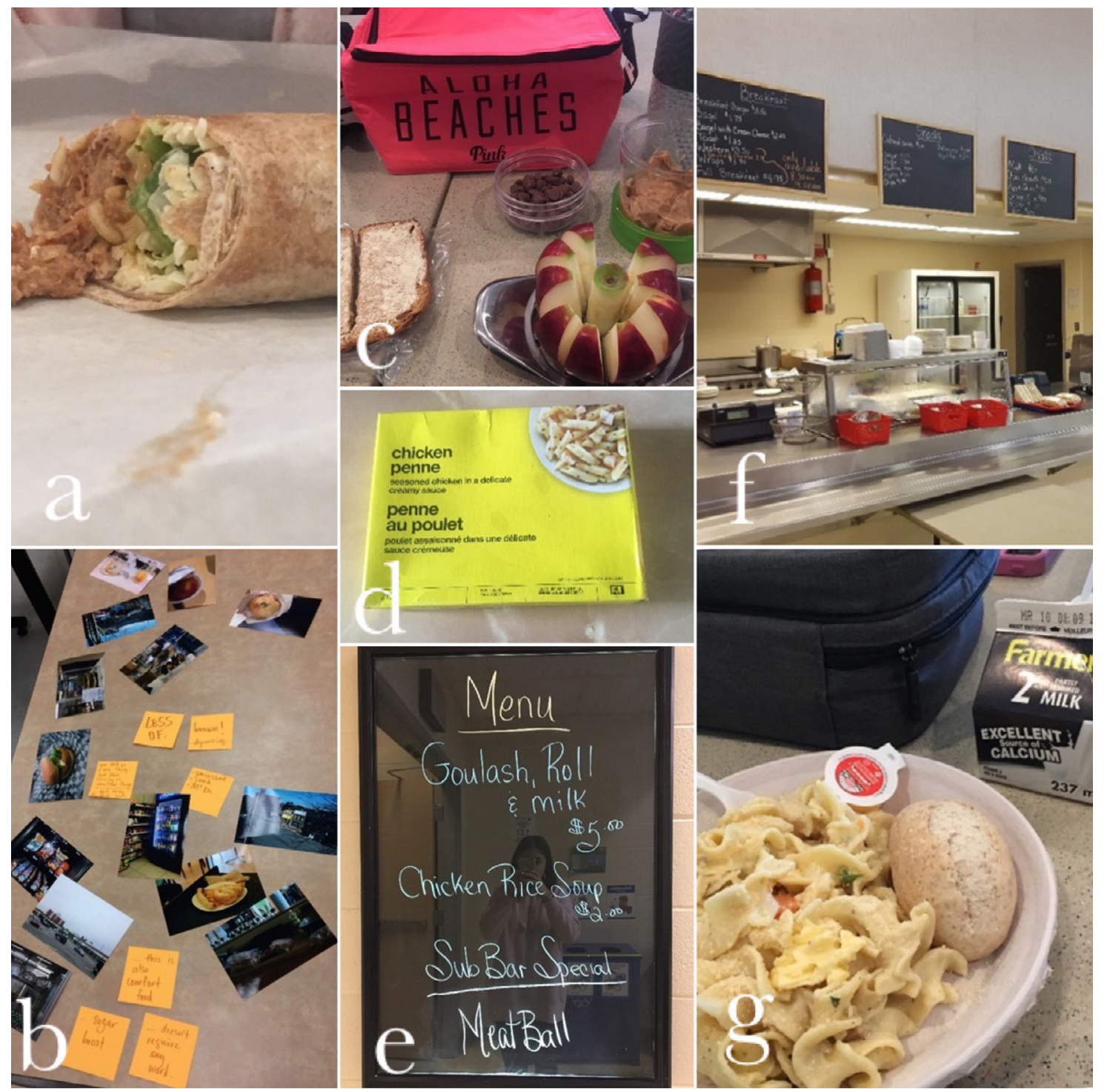

Figure 2. Photos from theme 2. (a) Photo illustrating typical cafeteria food. (b) Photo grouping of foods youths wanted less of, showing mostly school food. (c, d) Comparison of foods brought from home requiring (c) more and (d) less time and effort. (e) School menu board remarked by participants as dominated by meat options. (f) School cafeteria serving area, in which youths noted the fruit bowl was empty. (g) School cafeteria meal described as unappetizing.

to sit down and eat food, which I don't always have time for.

Other youths reflected on the time required to eat and the schedule allotted by schools for breaks, which varied. Youths from schools with short lunch periods noted that they had to choose between eating and performing other activities, doing homework, or socializing. Other youths mentioned the variability from class to class regarding whether eating in class or short breaks were permitted, which highlighted a need for consistency.
A final subtheme was related to price. Youths consistently identified healthier options as more expensive and perceived this to be intertwined with quality such that healthier cafeteria options tended to be more expensive but not necessarily appetizing, so they were not sure whether these foods were worth the investment (Figure $2 \mathrm{a}$ and $\mathrm{g}$ ). Youths discussed how they had limited funds and restricted opportunities to gain them, because balancing employment with other commitments can be challenging. They also discussed their perception of school food finances. They reflected on their understanding that it would be more expensive for cafeterias to purchase healthy ingredients, it would require more time and staff to prepare such food, and therefore the food would cost more. They perceived that food needed to be sold at schools for a profit. One youth said, "They charge us a lot and the food's not great." However, another youth suggest that "if they got rid of some of the things people don't enjoy, they would have 
the budget for things people do enjoy." This indicates the value of understanding and collecting the perspectives of youths, which will be discussed subsequently.

\section{Theme 3: Social Influence: Everything Revolves Around Food}

All youths discussed the relation between food and social influences, or food as being social. Youth discussed this in reference to food as reward, role modeling, bringing people together, and sharing. Youth acknowledged that they get rewarded with food in their schools, to encourage participation in educational and extracurricular events, as well as in fund-raising initiatives. One youth described the photo in Figure 3a: "This is a cupcake sale we did, and people swarmed the cupcakes." Participants also discussed role modeling as a form of social influence in school food, highlighting key figures who promoted healthy eating by eating well themselves or by supporting student access. Some teachers were identified as having food baskets in their classrooms to provide students with snacks if they were hungry. This form of accessibility was highly regarded by participants.

Youth discussed and demonstrated their perception that food brings people together. They enjoyed eating and preparing food together, such as the dish in Figure $3 \mathrm{~b}$, and emphasized how food was central to social and special occasions, such as school carnivals, holidays, and sporting events. They identified eating as something often done with friends and highlighted the school lunch break as an important time for socializing. One said, "It's very much a social thing [...] we do often make eating a social activity." Another remarked,

I feel like everything revolves around food. [...] First question is, like, where are we going to eat?

[...] Everything's just very food specific.

This also connected to the theme of spaces and places, in that where youth spend their breaks was perceived as significant. Youths wanted

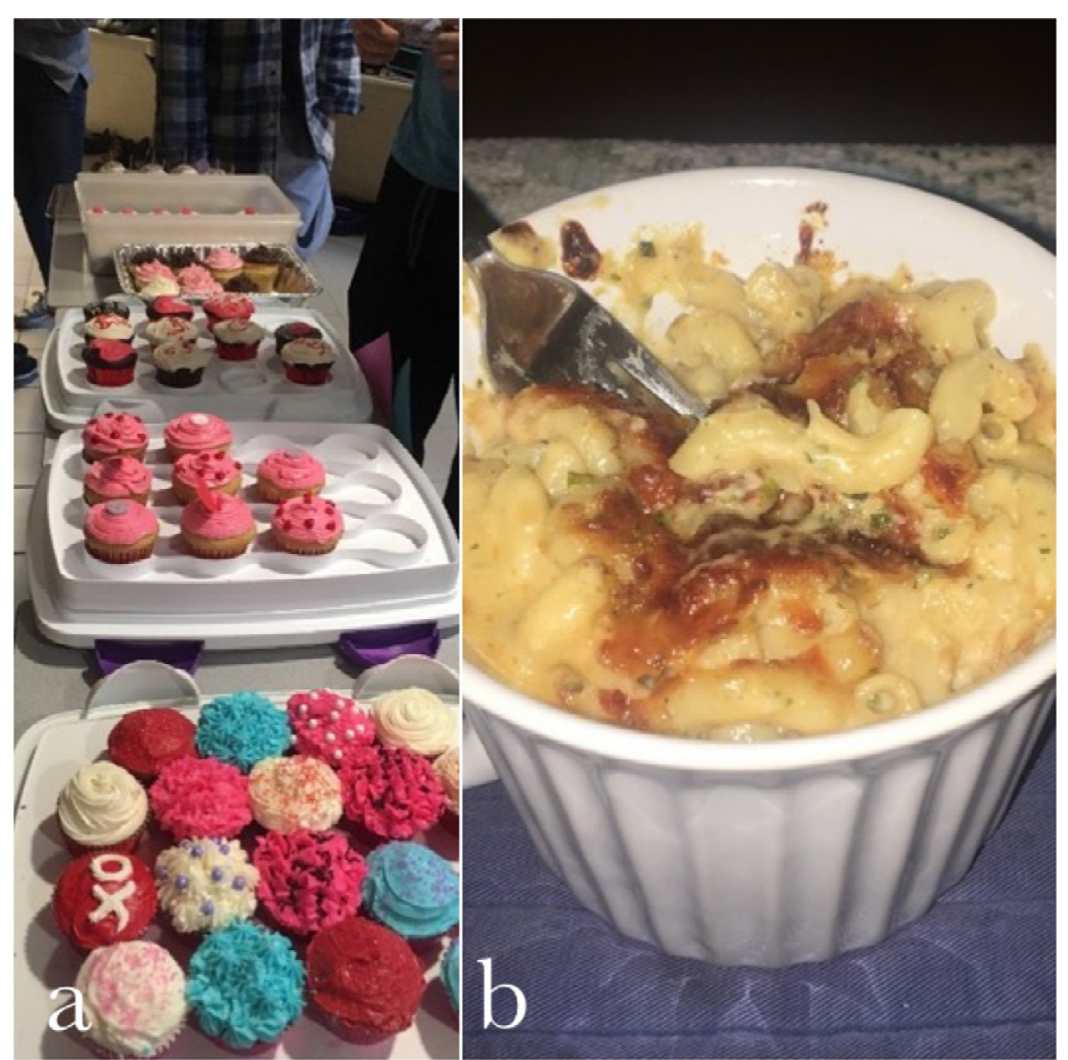

Figure 3. Photo from theme 3. (a) Cupcake sale at school. (b) Homemade macaroni and cheese dish, which was discussed as something often prepared together and socially shared by participants.

comfortable and safe spaces to eat and socialize, such as quiet classroom spaces that welcomed diverse groups of youth to congregate, converse, and eat together; they highlighted important alternatives to cafeterias, which were perceived of as loud and chaotic. One youth said,

\section{I think the drama room is like calm. [...] Everybody is kind of in their own groups, so there is a lot of different conversations hap- pening. [...] And then there is, like, a kid playing the piano and singing. [...] I think it's the peo- ple, maybe, and the environment where it's a lot more calm than maybe the cafeteria, where people are screaming.}

Finally, youths emphasized the social importance of sharing food. They discussed buying or bringing food and sharing, especially with their close friends, whose taste preferences they understood, as illustrated in Figure 3b. They discussed how they enjoyed sharing food, that it contributed to a sense of community, and how this was common and accepted in schools. One youth said, "I think our school, in general, is really sharing focused." The youths discussed how they took turns spending money at school or restaurants, splitting the cost of food, bringing food to share, and ensuring their friends and classmates had enough to eat. One participant said,

\begin{abstract}
I buy my friends food all the time because I want them to be fed and I have a job, and I can. So, like, if I notice that someone doesn't have something, I'll be, like, 'I'm going to get myself something at the cafeteria. Do you want anything?
\end{abstract}

Theme 4: Prioritizing the Youths' Voice

Youths thought that they were lacking significant or meaningful opportunities to have a say regarding school food. Overall, they believed there was little opportunity to provide feedback about 


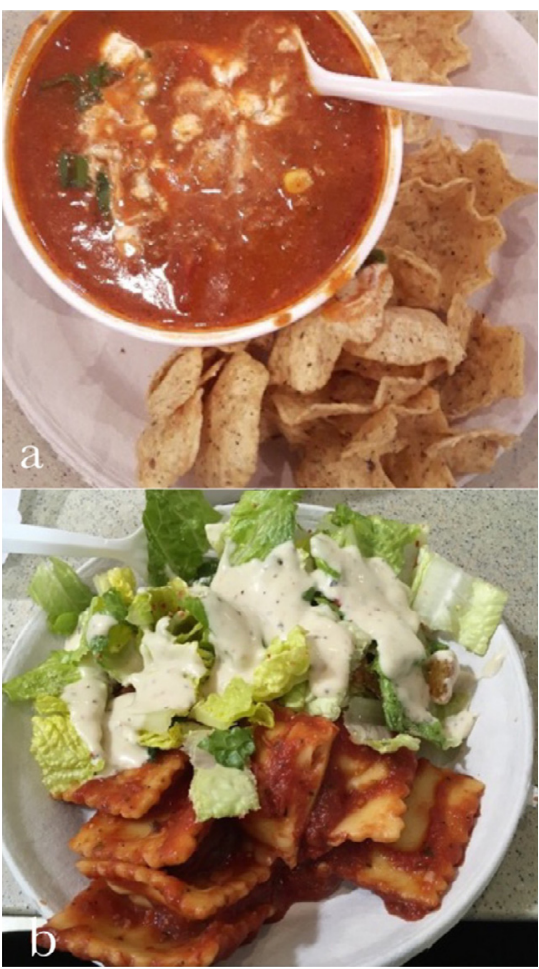

Figure 4. Photos from theme 4. (a, b) Examples of cafeteria meals that were enjoyed (a) more and (b) less, respectively, and for which youth did not have an opportunity to provide feedback.

the food served and sold in schools. For example, Figure $4 a$ and $b$, the taco soup was enjoyed but removed from the menu without explanation, whereas the ravioli continued to be served although youths did not enjoy it. Youths suggested that staff and decision makers may be unaware of the extent to which cafeteria selections are enjoyed. One said,

If they knew more what kids liked and disliked and, like, and what kids wanted more of or less of, I think that would be important.

They also acknowledged that cafeterias faced challenges regarding serving food that met policy guidelines. One youth said,

They don't get a lot of feedback from the students, so maybe they are just oblivious to the fact that nobody likes the food? [...] I think it is also hard for them because they have strict guidelines as to what they are allowed to use.
Some participants thought there was a perception by adults that youths only wanted to eat unhealthy foods and that speed, convenience, and profit were prioritized over quality and taste.

Youths believed that schools should have a mechanism to provide feedback about food, but they had mixed views about whether their voices would be heard or their perspectives considered. Some highlighted the need for more communication. One said, "I've never seen a menu before. They don't hand them out." Another suggested, "Let us help you!" although others questioned the concepts of power and decisionmaking and were unsure about their potential influence. Youths also highlighted inconsistencies in communication and modeling. One stated, "They tell us to eat healthy but don't serve healthy food." Youths suggested involving students in school food operations as an option for change, such as having students work with staff. One youth said that "Some of the international students could help, like, make their dishes. [...] It would be so much better," which might contribute to variety, quality, and the sense of community. They also acknowledged that youths were busy, and many might not have the time or interest in driving changes in school food but would like the opportunity to be more involved.

\section{DISCUSSION}

This study aimed to engage youth in a critical analysis of their school food environments using photovoice. Youth were able to record, reflect on, and critique their school food environments, engage in participatory analysis, and facilitate the development of themes presented in this article, which both affirm and expand on existing school food literature. Through this study, youths were engaged in generating data through photographs representing their experiences as well as participatory analysis using the photovoice methodology. ${ }^{27,29}$ Through the selection of photographs, contextualization using the SHOWeD method, and codifying, or participatory thematic analysis, youths offered a critical lens on their food environments and experiences. ${ }^{27,29}$
As outlined in the final theme, this type of authentic engagement was highly desired by youths, who described a lack of opportunity to provide feedback on their daily food experiences.

The first theme indicated that spaces and places were important to youths' food experiences. This was shown in other literature, ${ }^{36}$ which indicated that high school students tended to bring lunch from home, which was associated with increased fruit and vegetable intake. The importance of school food outside the cafeteria was particularly interesting; youths emphasized the value of safe and comfortable spaces for youths to eat and socialize in small groups. This indicates the need for future research and intervention to explore eating spaces beyond cafeterias.

The second theme identified key components for school food environments, including quality, variety, time, and price. Some of this was previously explored, ${ }^{17,37}$ including the concepts of time and convenience, and suggested that in some contexts, youths may find healthy eating to be inconvenient. Nevertheless, participants also enjoyed food preparation and cooking in certain contexts, especially when quality was improved. Youths' emphasis on food quality was also highlighted in the literature, ${ }^{18,38-40}$ which noted a preference for quality and healthy food, alongside other aspects of this work, such as communication and decision-making. Youths also mentioned an opportunity to better connect what is learned in the classroom with what is served in school cafeterias, which provides an opportunity for modeling.

The third emergent theme is related to the importance of social influences. Participants discussed the importance of socializing, but also more broadly discussed how food is social and an important part of society, which was highlighted in previous work. ${ }^{11,17,41-44}$ Finally, the importance of the youths' voice and its prioritization was highlighted in this work. Studies ${ }^{21,25,26,39}$ suggested a need to integrate youths' voice, but few actually offered the opportunity for meaningful engagement. School food research is continuing to reaffirm the value of engaging youths in 
transformational opportunities for engagement, including those using participatory approaches. $^{18}$

Including the youths' voice is important yet often excluded from discussions related to school policy and planning. Involving youths in issues that influence them, regardless of their potential complexity, was highlighted in previous work. ${ }^{20,26}$ Recruitment for this project proved to be both a strength and limitation. This project occurred outside the school system, which caused some sensitivity and uncertainty regarding participation that was challenging to navigate. Not wanting to burden the school system, the researchers conducted recruitment through community organizations, which were distanced from the school food environment. Nonetheless, this was also a strength, because participants were likely more diverse than if recruitment had occurred through specific schools. Other limitations of this project related primarily to time constraints and scheduling. Working with youths directly is challenging: their schedules are complex and require flexibility that goes beyond standard research procedures. The perspectives of youths who are harder to reach might also have been missed. Those who chose to participate likely had some interest in the subject matter, although this was mitigated by not recruiting directly through student or nutrition councils. Thus, their views may not be reflective of other youths within their schools.

\section{IMPLICATIONS FOR RESEARCH AND PRACTICE}

This project engaged Nova Scotia youths in a photovoice project to reflect critically on their school food environments. Although the small sample size of this project was consistent with the photovoice methodology, which should prioritize the depth and richness of data analysis and prolonged engagement with participants over sample size, ${ }^{35,45}$ this had implications for the findings, which should be interpreted accordingly. Important findings from this work and implications for practice include the youths' emphasis on real food, food environments that feel like home, and the value of spaces beyond school cafeterias. In addition, the youths in this project mentioned their wishes for a variety of healthy, highquality food that was affordable, and the need for choice and autonomy in making food decisions. They also highlighted the importance of food being social, bringing people together, and sharing. Finally, youths discussed their perception of inconsistent messaging and their desire to be more involved in school food decision making. Future research might continue to engage youth in the process and explore these ideas in more depth. These results contribute to a growing body of literature aiming to elevate youths' voices regarding issues relevant to their lives, inviting fresh perspectives and innovative solutions to complex problems. These findings may be interesting to school food stakeholders and decision makers and those implementing and evaluating school food policy. They could be also explored in other contexts with larger groups to compare and add additional perspectives.

\section{ACKNOWLEDGMENTS}

The authors would like to acknowledge the youths who took part in this project, and the Heartwood Centre for Youth Development for their support of this work. This work was supported by the Canadian Institutes of Health Research (FRN: 335426) and the Max Bell Foundation. The funders had no role in the design, analysis, or writing of this article.

\section{REFERENCES}

1. Hernandez K, Engler-Stringer R, Kirk S, Wittman H, McNicholl S. The case for a Canadian national school food program. Can Food Stud. 2018;5:208-229.

2. Kirk SF, Kuhle S, McIsaac J-LD, et al. Food security status among grade 5 students in Nova Scotia, Canada and its association with health outcomes. Public Health Nutr. 2015;18:2943-2951.

3. Blanck HM, Kim SA. Creating supportive nutrition environments for population health impact and health equity: an overview of the Nutrition and Obesity Policy Research and Evaluation Network's efforts. Am J Prev Med. 2012;43(suppl 2):S85-S90.
4. Hobbs SH. Getting from fat to fit: the role of policy in the obesity disaster. Health Pap. 2008;9:8-21.

5. Morin P, Demers K, Robitaille É, Lebel A, Bisset S. Do schools in Quebec foster healthy eating? An overview of associations between school food environment and socio-economic characteristics. Public Health Nutr. 2015;18:1635-1646.

6. Penney TL, Almiron-Roig E, Shearer C, McIsaac J-L, Kirk SFL. Modifying the food environment for childhood obesity prevention: challenges and opportunities. Proc Nutr Soc. 2014;73:226-236.

7. Wordell D, Daratha K, Mandal B, Bindler R, Butkus SN. Changes in a middle school food environment affect food behavior and food choices. J Acad Nutr Diet. 2012;112:137-141.

8. Browning HF, Laxer RE, Janssen I. Food and eating environments: in Canadian schools. Can J Diet Pract Res. 2013;74:160-166.

9. Raine KD. Improving nutritional health of the public through social change: finding our roles in collective action. Can J Diet Pract Res. 2014;75:160-164.

10. McIsaac J-LD, Shearer CL, Veugelers PJ, Kirk SFL. Moving forward with school nutrition policies: a case study of policy adherence in Nova Scotia. Can J Diet Pract Res. 2015;76:172-177.

11. McIsaac J-LD, Read K, Veugelers PJ, Kirk SFL. Culture matters: a case of school health promotion in Canada. Health Promot Int. 2017;32:207-217.

12. McIsaac J-LD, Mumtaz Z, Veugelers PJ, Kirk SFL. Providing context to the implementation of health promoting schools: a case study. Eval Program Plann. 2015;53:65-71

13. Fung C, McIsaac J-LD, Kuhle S, Kirk SFL, Veugelers PJ. The impact of a population-level school food and nutrition policy on dietary intake and body weights of Canadian children. Prev Med. 2013;57:934-940.

14. Park S, Sappenfield WM, Huang Y, Sherry B, Bensyl DM. The impact of the availability of school vending machines on eating behavior during lunch: the Youth Physical Activity and Nutrition Survey. J Am Diet Assoc. 2010;110:1532-1536.

15. Rovner AJ, Nansel TR, Wang J, Iannotti RJ. Food sold in school vending machines is associated with overall student dietary intake. $J$ Adolesc Health. 2011;48:13-19.

16. Taber DR, Chriqui JF, Chaloupka FJ. Differences in nutrient intake associated with 
state laws regarding fat, sugar, and caloric content of competitive foods. Arch Pediatr Adolesc Med. 2012;166:452-458.

17. Spencer R, McIsaac J-L, Kirk S. Food for thought: engaging youth in creative knowledge sharing of school food experiences. Int J Health Wellness Soc. 2017;7:53-63.

18. Asada Y, Hughes AG, Read M, Schwartz MB, Chriqui JF. High school students' recommendations to improve school food environments: insights from a critical stakeholder group. $J$ Sch Health. 2017;87:842-849.

19. Orme J, Jones M, Salmon D, Weitkamp E, Kimberlee R. A process evaluation of student participation in a whole school food programme. Health Educ. 2013;113:168-182.

20. Jones S, Spence M, Hardin S, Clemente N, Schoch A. Youth Can! Results of a pilot trial to improve the school food environment. J Nutr Educ Behav. 2011;43:284-287.

21. Linton LS, Edwards C, Woodruff S, Millstein R, Moder C. Youth advocacy as a tool for environmental and policy changes that support physical activity and nutrition: an evaluation study in San Diego County. Prev Chronic Dis. 2014;11:E46.

22. Kumar GS, Bryan M, Bayakly R, Drenzek C, Merlo C, Perry GS. Reported motivations for and locations of healthy eating among Georgia high school students. J Sch Health. 2017;87: 353-362.

23. Turner L, Chaloupka FJ. Slow progress in changing the school food environment: nationally representative results from public and private elementary schools. J Acad Nutr Diet. 2012;112: 1380-1389.

24. Findholt NE, Michael YL, Davis MM. Photovoice engages rural youth in childhood obesity prevention. Public Health Nurs. 2011;28:186-192.

25. Fleming J. Young people's involvement in research: still a long way to go? Qual Soc Work. 2011;9:207-223.
26. Ozer EJ, Wright D. Beyond school spirit: the effects of youth-led participatory action research in two urban high schools. J Res Adolesc. 2012;22: 267-283.

27. Wang C, Burris MA. Photovoice: concept, methodology, and use for participatory needs assessment. Health Educ Behav. 1997;24:369-387.

28. Wang C. Photovoice: a participatory action research strategy applied to women's health. J Womens Health. 1999;8:185-192.

29. Wang C, Yi WK, Tao ZW, Carovano K. Photovoice as a participatory health promotion strategy. Health Promot Int. 1998;13:75-86.

30. Brazg T, Bekemeier B, Spigner C, Huebner CE. Our community in focus: the use of photovoice for youth-driven substance abuse assessment and health promotion. Health Promot Pract. 2011;12:502-511.

31. Findholt NE, Michael YL, Davis MM. Photovoice engages rural youth in childhood obesity prevention. Public Health Nurs. 2011;28:186-192.

32. Heidelberger L, Smith C. The food environment through the camera lenses of 9- to 13-year-olds living in urban, low-income, Midwestern households: a photovoice project. J Nutr Educ Behav. 2015;47:437-445

33. Royce SW, Parra-Medina D, Messias DH. Using photovoice to examine and initiate youth empowerment in community-based programs: a picture of process and lessons learned. Calif $J$ Health Promot. 2006;4:80-91.

34. Strack RW, Magill C, McDonagh K. Engaging youth through photovoice. Health Promot Pract. 2004;5:49-58.

35. Wang C. Youth participation in photovoice as a strategy for community change. J Community Pract. 2006;14: 147-161.

36. Jones AC, Hammond D, Reid JL, Leatherdale ST. Where should we eat? Lunch source and dietary measures among youth during the school week. Can J Diet Pract Res. 2015;76: 157-165.

37. Harrison M, Jackson LA. Meanings that youth associate with healthy and unhealthy food. Can J Diet Pract Res. 2009; 70:6-12.

38. Bauer KW, Larson NI, Nelson MC, Story M, Neumark-Sztainer D. Socioenvironmental, personal and behavioral predictors of fast-food intake among adolescents. Public Health Nutr. 2009; 12:1767-1774.

39. Bauer KW, Yang YW, Austin SB. How can we stay healthy when you're throwing all of this in front of us?" Findings from focus groups and interviews in middle schools on environmental influences on nutrition and physical activity. Health Educ Behav. 2004;31:34-46.

40. Gosliner W, Madsen KA, WoodwardLopez G, Crawford PB. Would students prefer to eat healthier foods at school? J Sch Health. 2011;81:146-151.

41. Bruening M, Eisenberg M, MacLehose R, Nanney MS, Story M, NeumarkSztainer D. Relationship between adolescents' and their friends' eating behaviors: breakfast, fruit, vegetable, whole-grain, and dairy intake. $J$ Acad Nutr Diet. 2012;112:1608-1613.

42. Salvy S-J, Bowker JC. Peers and obesity during childhood and adolescence: a review of the empirical research on peers, eating, and physical activity. $J$ Obes Weight Loss Ther. 2014;4:207.

43. Sawka KJ, McCormack GR, NettelAguirre A, Swanson K. Associations between aspects of friendship networks and dietary behavior in youth: findings from a systematized review. Eat Behav. 2015;18:7-15.

44. Shin H-S, Valente TW, Riggs NR, et al. The interaction of social networks and child obesity prevention program effects: the pathways trial. Obesity (Silver Spring). 2014;22:1520-1526.

45. Catalani C, Minkler M. Photovoice: a review of the literature in health and public health. Health Educ Behav. 2010; 37:424-451. 